\title{
Estudo de 127 casos de violência sexual contra vulneráveis do sexo masculino atendidos no Programa Bem Me Quer em 2014
}

\author{
Study of 127 cases of sexual violence against vulnerable males \\ who attended the program Bem Me Quer in 2014
}

\author{
Carlos Henri Gomes Filho', Ivan Dieb Miziara² \\ Nataly Cristina Reis Uzelin ${ }^{3}$, Daniele Muñoz Gianvecchio ${ }^{3}$
}

DOI: http://dx.doi.org/10.11606/issn.2317-2770.v26i1p13-20

\begin{abstract}
Gomes Filho CH, Miziara ID, Uzelin NCR, Gianvecchio DM. Estudo de 127 casos de violência sexual contra vulneráveis do sexo masculino atendidos no Programa Bem Me Quer em 2014. Saúde, Ética \& Justiça. 2021;26(1):13-20.

RESUMO: Violência sexual é qualquer ato sexual indesejado voltado contra a sexualidade de uma pessoa, praticado por qualquer pessoa, independentemente de sua relação com a vítima, em qualquer cenário. A literatura sobre violência sexual contra crianças do sexo masculino é escassa. O objetivo deste trabalho é descrever os atos libidinosos referidos por vulneráveis do sexo masculino atendidos em 2014 na Equipe de Perícias Médico Legais Bem Me Quer do Instituto Médico Legal do Estado de São Paulo (IML), além de dados epidemiológicos, como idade das supostas vítimas, relação interpessoal com o alegado agressor, tempo ocorrido entre a suposta violência e a perícia, presença de lesões corporais e positividade na coleta de espermatozoides. Foi realizada uma análise retrospectiva de dados coletados de perícias realizadas no ano 2014. Após aplicação dos critérios de inclusão e exclusão, foram estudados os laudos de 127 vulneráveis do sexo masculino. O suposto ato libidinoso referido mais frequente foi o coito anal (25\%). A média de idade das supostas vítimas foi 6,85 anos. O alegado agressor mais comum foi um conhecido (25\%). Em $23 \%$ dos casos, o exame pericial ocorreu dentro das primeiras 24 horas, e em $10 \%$ dos casos foi constatada lesão corporal de natureza leve. Não houve positividade da coleta de espermatozoide, o que prejudica a comprovação da violência sexual.
\end{abstract}

DESCRITORES: Maus-Tratos Infantis; Meninos; Medicina Legal.

\footnotetext{
1. Hospital das Clínicas da Faculdade de Medicina da Universidade de São Paulo.

2. Universidade de São Paulo. Faculdade de Medicina. Departamento de Medicina Legal, Ética Médica e Medicina Social e do Trabalho.

3. Instituto Médico Legal do Estado de São Paulo - EPML Bem Me Quer.

Endereço para correspondência: Carlos Henri Gomes Filho. E-mail: carloshenri_gf@hotmail.com
} 


\section{INTRODUÇ̃̃̃O}

violência sexual é definida como
qualquer ato sexual, tentativa de
obter um ato sexual, comentários ou investidas sexuais indesejadas, ou atos direcionados ao tráfico sexual ou, de alguma forma, voltados contra a sexualidade de uma pessoa usando a coação, praticados por qualquer pessoa, independentemente de sua relação com a vítima, em qualquer cenário, inclusive em casa e no trabalho, mas não limitado a eles ${ }^{1}$. Estimativas indicam que os Estados Unidos sofrem com milhões de casos anualmente, sendo que uma em cada três mulheres e um em cada quatro homens experienciam violência sexual envolvendo contato físico durante a vida ${ }^{2}$. Como há subnotificação, o cenário real deve ser mais grave. As vítimas têm dificuldade em procurar ajuda por vergonha, culpa ou medo de não serem acreditadas ${ }^{1}$.

Historicamente, o estudo de violência e maustratos contra crianças remonta aos trabalhos de Ambroise Tardieu. Em sua publicação "Étude médicolégale sur les attentats aux moeurs", de 1857, ele analisou 632 casos de abuso sexual em mulheres, sendo que a maioria das vítimas eram crianças. Apesar de seus trabalhos, este não foi capaz de convencer a comunidade médica da época sobre a prevalência de maus-tratos à criança dentro do próprio ambiente familiar ${ }^{3}$. Apesar das definições legais sobre a violência sexual variarem de acordo com a legislação de cada país, a maioria delas considera a imposição da força física, da intimidação e a não concordância da vítima para a incriminação do autor da violência ${ }^{4}$.

Uma forma específica de violência, que é pouco discutida na literatura especializada, é a violência sexual contra crianças do sexo masculino ${ }^{5}$. A maioria dos estudos focaliza vítimas do sexo feminino, acreditando que o abuso sexual de meninos seja incomum e que pode trazer pouco impacto sobre os meninos e sobre seu desenvolvimento. Cabe considerar que provavelmente muitos meninos não revelam o abuso por sentirem que poderão não ser acreditados. Os meninos seriam vítimas silenciadas por medo de expor sua masculinidade, assim como seus sentimentos de dependência, de medo e de vulnerabilidade ${ }^{6}$.

O Estatuto da Criança e do Adolescente (Lei ${ }^{\circ}$ 8.069 , de 13 de julho de 1990) ${ }^{7}$ é um dos principais dispositivos legais brasileiros que visam proteger a criança e o adolescente. Para os efeitos dessa lei, conforme descrito no Art. $2^{\circ}$, são consideradas crianças todas as pessoas com até doze anos de idade incompletos e adolescentes, as pessoas com idade entre doze e dezoito anos. Ainda em seu Art. $3^{\circ}$, é descrito que "a criança e o adolescente gozam de todos os direitos fundamentais inerentes à pessoa humana" e devem ter "todas as oportunidades e facilidades a fim de lhes facultar o desenvolvimento físico, mental, moral, espiritual e social, em condições de liberdade e de dignidade".

No Brasil, o Código Penal em seu artigo 217 define Estupro de Vulnerável como "Ter conjunção carnal ou praticar outro ato libidinoso com menor de 14 (catorze) anos: (Incluído pela Lei $\mathrm{n}^{\circ} 12.015$, de 2009)" ${ }^{\prime 8}$. Ainda, seu parágrafo primeiro acrescenta "Incorre na mesma pena quem pratica as ações descritas no caput com alguém que, por enfermidade ou deficiência mental, não tem o necessário discernimento para a prática do ato, ou que, por qualquer outra causa, não pode oferecer resistência". Portanto, são considerados vulneráveis todos os indivíduos menores de 14 anos de idade, pessoas enfermas ou com deficiência mental e sem o necessário discernimento para o ato sexual, além de pessoas que, por qualquer motivo, não são capazes de oferecer resistência. Não há, portanto, legalidade em suposto consentimento que poderia ser concedido quando se trata de indivíduos abaixo de 14 anos.

A violência sexual pode estar acompanhada de lesões corporais, as quais podem ser classificadas em leve, grave (causa incapacidade para as ocupações habituais por mais de 30 dias, perigo de vida, debilidade permanente de membro, sentido ou função ou aceleração do parto) ou gravíssima (causa incapacidade permanente para o trabalho, perda ou inutilização de membro, sentido ou função deformidade permanente ou aborto) conforme o artigo 129 do Código Penal Brasileiro $^{8}$

A perícia médica é necessária para demonstrar a materialidade do crime de estupro de vulnerável. É feita por médico legista mediante requerimento de autoridade judiciária ou policial. Em caso de recusa, deve ser registrada a não autorização, dado que não é possível realizar o exame sexológico sem colaboração e consentimento de quem será periciado ${ }^{9}$.

Certas manifestações devem ser levadas em conta, como mudança brusca de comportamento com relação aos amigos, medo de determinadas pessoas ou lugares, recusa ao exame, resposta pronta e imediata negando ter sido tocada por adulto, uso de expressões ligadas ao ato sexual, insinuações sobre práticas sexuais ou determinados indivíduos, entre outros ${ }^{10}$. O médicolegista não deve fazer juízo de valor ou emitir opiniões pessoais acerca do ocorrido. O Código de Ética Médica, em seu Art. 98, traz que é vedado ao perito “deixar de atuar com absoluta isenção quando designado para servir como perito ou como auditor, bem como ultrapassar os limites de suas atribuições e de sua competência"11.

Durante o exame médico pericial de vítimas 
do sexo masculino, deve-se proceder ao exame físico completo, com especial atenção para a avaliação dos genitais, região perianal e anal e região oral. $\mathrm{O}$ médico legista deve coletar material biológico das regiões suspeitas, a depender do prazo decorrido entre o fato e o exame médico, com a finalidade de realizar pesquisas de espermatozoides e de antígeno prostático específico (PSA) e/ou exame genético. A pesquisa de espermatozoides tem um papel de destaque na avaliação pericial, dado que a positividade da coleta de espermatozoides é um elemento que favorece o diagnóstico de certeza da violência sexual ${ }^{12,13}$. Como o tempo de permanência de espermatozoides é variável, a perícia deve ser feita no menor intervalo de tempo possível, sendo que o tempo ideal de coleta é abaixo de seis horas para swabs orais e vinte e quatro horas para swabs anorretais ${ }^{14}$.

Na cidade de São Paulo, em 2001, foi formalizada uma parceria entre a Secretaria de Segurança Pública e a Secretaria de Saúde, através do Decreto no 46.369, de 14 de dezembro de 2001, e criado o Programa Bem Me Quer, cujo objetivo é promover amparo à vítima de abuso sexual ${ }^{15}$. Há uma equipe do IML especializada no atendimento de casos de violência sexual, EPML Bem Me Quer, localizada dentro do Hospital (Centro de Referência à Saúde da Mulher) de forma que a vítima recebe atendimento pericial, médico assistencial, psicológico e social num mesmo ambiente físico; além disso, o Programa conta com viaturas para realizar o transporte da vítima da delegacia de polícia até o hospital. Esse programa atende todos os casos de violência sexual ocorridos na cidade de São Paulo, contra mulheres e meninos até 14 anos de idade, os quais são o foco deste trabalho.

\section{OBJETIVOS}

\section{Objetivo primário}

Descrever a natureza e a frequência dos atos libidinosos referidos por vulneráveis do sexo masculino (menores de 14 anos) vítimas de violência sexual atendidos pela Equipe de Perícias Médico Legais Bem Me Quer do Instituto Médico Legal do Estado de São Paulo em 2014.

\section{Objetivos secundários}

Verificar:

- idade das vítimas

- identidade do alegado agressor;

- tempo decorrido entre o abuso alegado e a perícia médico-legal;

- $\quad$ presença de lesão corporal;
- positividade da coleta de espermatozoides.

\section{MÉTODO}

Análise retrospectiva e descritiva de dados obtidos em laudos de exames sexológicos realizados pela Equipe de Perícias Médico Legais Bem Me Quer do IML. Foram analisados os primeiros 1.000 casos de violência sexual atendidos na EPML Bem Me Quer em 2014. Foram analisados apenas aqueles realizados em indivíduos do sexo masculino, com idade inferior a 14 anos, o que resultou em 127 laudos. As variáveis analisadas foram: ato libidinoso referido pela suposta vítima, idade da suposta vítima, relação interpessoal com o suposto agressor, intervalo de tempo entre o ato sexual relatado e a avaliação médico-legal, presença de lesão corporal identificável ao exame (leve, grave ou gravíssima), presença de espermatozoides (em região anal e/ou cavidade oral). Também foi realizado levantamento de artigos nas bases de dados PubMed/ MEDLINE e SciELO com uso dos descritores "maustratos infantis", "meninos" e "medicina legal", seguido de seleção de artigos relevantes para o trabalho, além de leitura de manuais e livros de referência no assunto.

\section{RESULTADOS}

Após análise de 127 laudos periciais realizados em 2014 em vítimas do sexo masculino até 14 anos de idade, foram obtidos os resultados elencados a seguir.

A Tabela 1 apresenta o tipo de ato libidinoso referido pelas supostas vítimas. $\mathrm{O}$ ato libidinoso referido mais frequente foi o coito anal (coito anal isolado ou associado a outro ato) em $25 \%$ dos casos, seguido por manipulação em ânus da vítima (isolado ou associado a outro ato) em $15 \%$. Os atos libidinosos envolvendo a região anal somados (coito anal, coito anal e outros, manipulação em ânus da vítima, vermelhidão em ânus, manipulação em ânus da vítima e outros, sangramento anal) representaram $43 \%$. Os atos libidinosos envolvendo a manipulação da genitália da vítima representam $15 \%$ dos casos. O total de casos envolvendo felação (isolado ou associado a outro ato), que é a prática de estimular o pênis com a boca ou a língua ${ }^{16}$, foi referido em $8 \%$. Embora 2\% tenham negado ato libidinoso, a perícia foi realizada por ter havido denúncia de terceiros às autoridades.

O Gráfico 1 apresenta a distribuição das supostas vítimas de acordo com a idade. Ocorreram 35 casos na faixa etária de 0 a 4 anos (28\%), 66 casos na faixa etária de 5 a 9 anos (52\%) e 26 casos na faixa etária de 10 a 13 anos (20\%). A média de idade foi 6,85 anos, a moda 6 anos e a mediana 6 anos. 
TABELA 1 - Tipo de ato libidinosos referido

\begin{tabular}{lcc}
\hline Ato libidinoso referido & Número de casos & Percentual \\
\hline Coito anal e outros & 18 & $14 \%$ \\
Manipulação em ânus da vítima & 17 & $13 \%$ \\
Coito anal & 14 & $11 \%$ \\
Outros & 14 & $11 \%$ \\
Não consta & 11 & $9 \%$ \\
Não sabe referir & 10 & $8 \%$ \\
Manipulação de genitais da vítima e outros & 10 & $8 \%$ \\
Manipulação de genitais da vítima & 9 & $7 \%$ \\
Felação e outros & 6 & $5 \%$ \\
Manipulação em genitais do agressor & 4 & $3 \%$ \\
Felação & 4 & $3 \%$ \\
Vermelhidão em ânus & 3 & $2 \%$ \\
Nega ocorrência de ato libidinoso & 3 & $2 \%$ \\
Manipulação em ânus da vítima e outros & 2 & $2 \%$ \\
Presença de sangramento anal & 1 & $1 \%$ \\
Beijo & 1 & $1 \%$ \\
\hline Total & $\mathbf{1 2 7}$ & \\
\hline
\end{tabular}

GRÁFICO 1 - Número de vítimas por idade

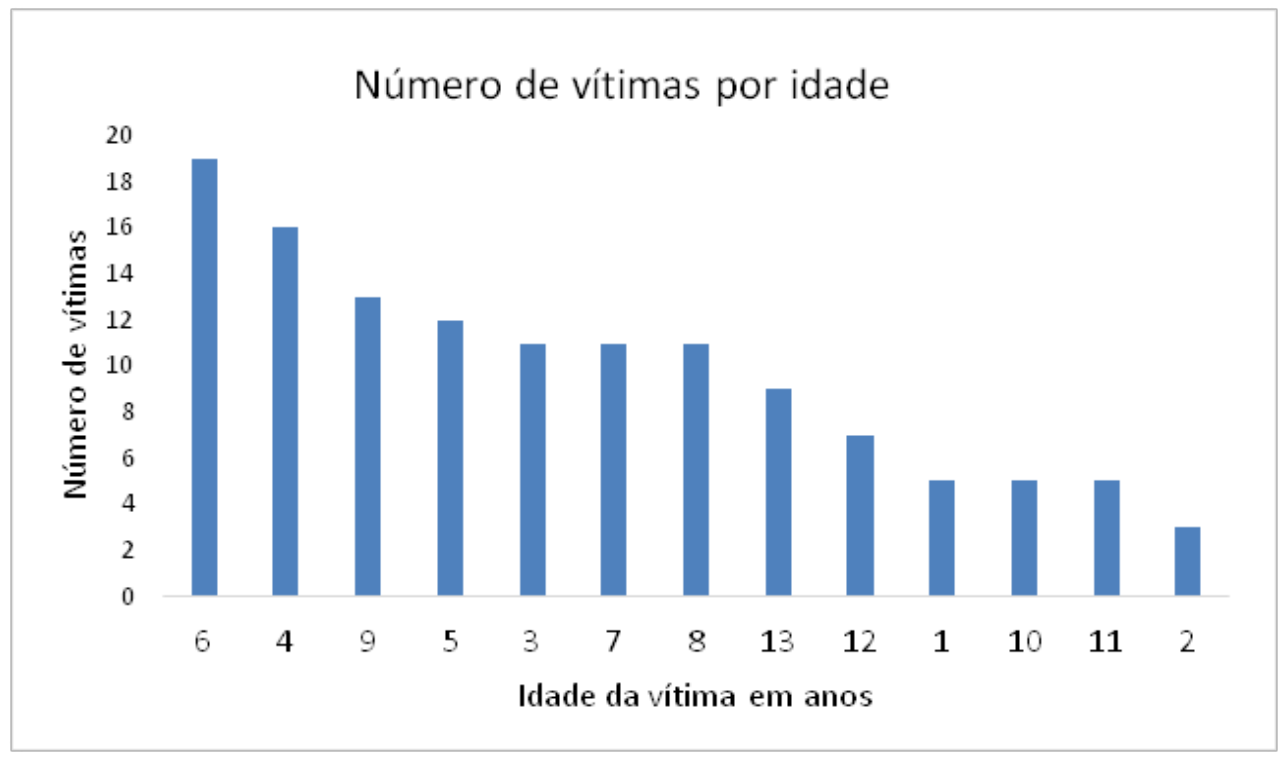

A Tabela 2 apresenta a distribuição dos agressores. Os agressores identificados como masculinos representaram $80 \%$ do total, enquanto os outros $20 \%$ não foram identificados. Todos os casos de parentes somados (pai, primo, irmão e tio) representaram $37 \%$.

A Tabela 3 apresenta a distribuição dos casos em relação ao tempo passado entre a violência e o ato pericial. Em $23 \%$ dos casos, o tempo foi de até um dia.
Em 34\% o tempo decorrido foi de 72 horas (até 3 dias).

A Tabela 4 demonstra que a avaliação médicoforense identificou presença de lesão corporal leve em 13 casos (10\%). Dentre os laudos sexológicos analisados não foram caracterizadas lesões corporais graves ou gravíssimas. Foi realizada coleta de material biológico da região anal para pesquisa de espermatozoide em 73 casos, além de coleta de material da cavidade oral em 37 casos. Não foram encontrados resultados positivos. 
Gomes Filho $\mathrm{CH}$ et al. Estudo de 127 casos de violência sexual contra vulneráveis do sexo masculino atendidos no Programa.

TABELA 2 - Distribuição do suposto agressor

\begin{tabular}{lcc}
\hline SUPOSTO AGRESSOR & NÚMERO DE CASOS & PERCENTUAL \\
\hline Conhecido & 32 & $25 \%$ \\
Pai & 30 & $23 \%$ \\
Outro & 11 & $9 \%$ \\
Colega da escola & 11 & $9 \%$ \\
Primo & 8 & $6 \%$ \\
Não sabe referir & 7 & $6 \%$ \\
Vizinho & 6 & $5 \%$ \\
Irmão & 6 & $5 \%$ \\
Tio & 4 & $3 \%$ \\
Não consta & 4 & $3 \%$ \\
Padrasto & 3 & $2 \%$ \\
Desconhecido & 3 & $2 \%$ \\
Amigo & 1 & $1 \%$ \\
Colega do abrigo & 1 & $1 \%$ \\
\hline Total & 127 & \\
\hline
\end{tabular}

TABELA 3 - Intervalo de tempo decorrido entre a suposta violência e a perícia sexológica

\begin{tabular}{lcc}
\hline Tempo de ocorrência & Número de casos & Percentual \\
\hline 1 dia & 29 & $23 \%$ \\
1 a 2 dias & 6 & $5 \%$ \\
2 a 3 dias & 8 & $6 \%$ \\
3 a 30 dias & 20 & $16 \%$ \\
30 dias a 1 ano & 13 & $10 \%$ \\
Acima de 1 ano & 6 & $5 \%$ \\
Tempo incerto & 31 & $24 \%$ \\
Não consta & 14 & $11 \%$ \\
\hline Total Geral & $\mathbf{1 2 7}$ & \\
\hline
\end{tabular}

TABELA 4 - Presença de lesão corporal leve

\begin{tabular}{lc}
\hline \multicolumn{1}{c}{ Presença de lesão corporal leve } & Número de casos \\
\hline Não & 113 \\
Prejudicado & 1 \\
Sim & 13 \\
\hline Total Geral & $\mathbf{1 2 7}$ \\
\hline
\end{tabular}

\section{DISCUSSÃO}

A literatura médica é escassa em estudos sobre violência sexual contra crianças do sexo masculino, sendo uma questão que comumente aparece apenas dentro de trabalhos que abordam a questão da violência contra a criança de forma mais ampla, não tendo como foco esse tipo específico de violência.

Hobbs e Osman ${ }^{17}$, em 2007, analisaram coorte de meninos com lesões genitais em que houve suspeita de abuso. Foram estudadas lesões de 86 meninos atendidos em um serviço pediátrico da cidade de Leeds, na Inglaterra, entre os anos de 1983 a 2003. As lesões descritas nesse trabalho foram: queimaduras em 7 
meninos; contusões em 27; lesões incisas, lacerações ou cicatrizes em 39 e outras lesões traumáticas em 27 . As lesões descritas afetaram toda a genitália: 37 dos meninos tinham lesão no prepúcio; 29, na base do pênis; 14 , na glande; 2 , no meato urinário e 12 , no escroto. Martins e Jorge $^{18}$, em 2010, realizaram um estudo descritivo e de corte transversal para conhecer características do abuso sexual em crianças e adolescentes de zero a 14 anos, a partir de casos registrados nos Conselhos Tutelares e programas de atendimento no município de Londrina-PR, em 2006. Em 90,3\% dos casos também houve presença de lesão corporal, sendo que o segmento mais afetado foi a pelve $(93,1 \%)$, seguida pelos casos em que múltiplas regiões foram afetadas $(6,9 \%)$. Essa porcentagem de casos de lesão corporal é mais elevada do que a porcentagem de casos do estudo apresentado neste artigo (10\%); no entanto, esse dado pode estar mascarado, pois não houve separação entre casos de lesões contra meninas e contra meninos nos atendimentos de Londrina. Guimarães e Villela $^{19}$, em 2011, estudaram características da violência contra crianças e adolescentes atendidos no Instituto Médico Legal de Maceió, em Alagoas. Foram estudadas 303 vítimas de violência submetidas a exame de corpo de setembro de 2008 a março de 2009 . As crianças do sexo masculino somaram 39 casos, e a maioria das lesões foi classificada como leve. Modelli et al. ${ }^{20}$, em 2012, avaliaram a prevalência de abuso sexual e as dificuldades de examinar a genitália num estudo retrospectivo transversal e epidemiológico com 1762 crianças abaixo de 12 anos de idade atendidas no Instituto Médico Legal de Brasília entre 2008 e 2009, sendo que 238 (13,5\%) eram meninos. As principais alterações descritas em meninos foram fissuras, laceração, equimoses e dilatação anal. O exame não identificou lesões em $82 \%$ dos meninos atendidos. Esses dados reforçam a noção da violência sexual contra crianças ser de difícil identificação, dado que muitas vezes não ela deixa marcas visíveis.

Silva e Barroso $^{21}$, em 2017, estudaram características demográficas e clínicas de crianças que foram vítimas de violência sexual. Foi realizado estudo retrospectivo de 248 casos de violência sexual confirmada contra crianças com menos de 12 anos atendidas no Instituto de Medicina Forense de Salvador, Bahia, entre os anos 2005 e 2010 , sendo que $16,1 \%$ das vítimas eram do sexo masculino. Lesão anal ou perianal recente estava presente em 35 (87,5\%) dos casos confirmados de vítimas do sexo masculino. Em um único caso, a violência foi confirmada pela presença de lesão na genitália de um menino. Elgendy e Hassan ${ }^{22}$, em 2013, fizeram um estudo retrospectivo de casos de violência sexual contra crianças na cidade do Cairo, capital do Egito. Os dados foram obtidos de casos atendidos no Departamento Médico Legal entre 2005 e 2011. Foram avaliadas 1832 vítimas, sendo 57,9\% masculinas. Dentre estas, 5,8\% foram agressões intrafamiliares; $37,3 \%$ foram de sodomia contra meninos, sendo que coito anal $(52,3 \%)$ foi o tipo mais comum. Hohendorff et al. ${ }^{23}$, em 2014, estudaram 239 casos de violência sexual contra meninos de idade entre 2 e 18 anos notificados na Coordenadoria Geral de Vigilância em Saúde de Porto Alegre, entre 2009 e 2011. Houve penetração oral em $67,7 \%$ e penetração anal em $32,3 \%$ dos casos. Em nosso trabalho, o relato de atos libidinosos envolvendo a região anal (coito anal, manipulação em ânus, vermelhidão em ânus, sangramento anal) representou $43 \%$ dos casos, sendo que o coito anal representou $25 \%$ dos casos referidos. A manipulação da genitália foi relatada em $15 \%$ e a felação, em $8 \%$. Apenas $10 \%$ dos casos tiveram a presença de lesões corporais, as quais foram classificadas como leve. Foram relatadas vermelhidão em ânus em $2 \%$ dos casos e a presença de sangramento anal em $1 \%$ dos casos. Esses sinais podem ter associação com o abuso sexual, apoiando o relato da criança, no entanto, por si só não são provas de abuso ${ }^{24}$.

Salter ${ }^{25}$ entende que o abuso sexual é caracterizado pela diferença de poder entre vítimas e agressores em termos de idade. No estudo realizado por Hobbs e Osman ${ }^{17}$, em 2007, a idade média encontrada foi de 5 anos, e a mediana de 4 anos. No estudo de Aded et al. ${ }^{26}$, em 2007, de um total de 124 casos, o número de vítimas com idade abaixo de 15 anos foi de $81,45 \%$, sendo que $20,97 \%$ eram de vítimas do sexo masculino. Martins e Jorge ${ }^{18}$ em 2010, estudaram 186 casos, incluindo vítimas femininas e masculinas. Entre as vítimas, 25,8\% eram meninos. Entre os meninos, a faixa etária de 0 a 4 anos foi de $8,4 \%$, a faixa etária de 5 a 9 anos foi de $66,7 \%$, a faixa etária de 10 a 14 anos foi de 25,0\%. No trabalho de Modelli et al. ${ }^{20}$, em 2012, a idade média dos meninos estudados foi de 6,5 anos. No trabalho de Hohendorff et al. ${ }^{23}$, em 2014, houve predominância de meninos entre 7 e 12 anos de idade (55,2\%), seguida pelos de 2 a 6 anos $(26,4 \%)$ e 13 a $18(17,1 \%)$. Nosso estudo refere-se apenas a meninos com menos de 14 anos de idade, pois é o grupo atendido no Programa Bem Me Quer. A faixa etária de 0 a 4 anos representou $28 \%$, enquanto a faixa etária de 5 a 9 anos representou $52 \%$, e a faixa de 10 a 13 representou $20 \%$. A média de idade das vítimas foi de 6,85 anos, sendo que a moda foi 6 anos e a mediana 6 anos também, em outras palavras, crianças em fase escolar e com pouca capacidade de defesa.

Salter ${ }^{25}$, em 2017, sugere que há um elo entre a formação da identidade sexual masculina e a violência sexual. No estudo de Aded et al. ${ }^{26}$, em 2007, os agressores tinham algum vínculo com a vítima em 55 casos, sendo que $20(16,13 \%)$ foram atribuídos a responsáveis, pais ou padrastos; $35(28,23 \%$ ), a parentes (tios, avós, primos) ou conhecidos. Para Martins e Jorge ${ }^{18}$, em 2010, os agressores do sexo masculino corresponderam à maior parte com 97,3\% dos casos, enquanto a presença de agressoras mulheres foi de 2,1\%. Em relação ao vínculo, a maior frequência dos agressores foi de padrasto $(30,1 \%)$, outros parentes $(21,5 \%)$, além de vizinhos $(18,3 \%)$, seguidos por 
desconhecidos, amigos da família e o próprio pai. Nos casos estudados por Guimarães e Villela ${ }^{19}$, em 2011, a identidade da maioria dos agressores incluiu conhecidos fora da família e padrastos. Nos casos de Modelli et al. ${ }^{20}$, em 2012, entre os casos em que houve lesão identificada, o agressor era conhecido da vítima em 10 casos $(43,4 \%)$. Em 11 casos, o agressor era desconhecido. Nos casos analisados por Elgendy e Hassan ${ }^{22}$, em 2013, todos os agressores eram masculinos, sendo a maioria de fora do ambiente familiar (94,2\%). Para Hohendorff et al. ${ }^{23}$, em 2014, os principais agressores eram do sexo masculino, com 93,4\% dos casos, enquanto agressores femininos foram referidos em apenas 3\% dos casos. Os principais agressores foram amigos ou conhecidos $(28,7 \%)$, outros $(23,9 \%)$, pai $(16,6 \%)$, padrasto $(9,3 \%)$, tio $(8,5 \%)$, primo $(6,9 \%)$ e irmão (6\%). Diferente do trabalho feito no Cairo, a maioria dos agressores relatados em nosso estudo são do convívio da vítima. Agressores com vínculo familiar (pai, primo, irmão e tio) somaram $37 \%$ dos casos. Não houve relato de agressora feminina e o próprio pai foi o agressor em 23\% dos casos. Conhecidos representaram 32 casos $(25 \%)$, enquanto padrasto foi o agressor em apenas 3 casos (2\%). Apenas 3 desconhecidos foram identificados como agressores. Nossos dados reforçam a relevância da diferença de idade como elemento constitutivo do abuso, além de corroborarem com a noção de haver uma relação entre identidades masculinas e violência sexual.

No estudo de Silva e Barroso ${ }^{21}$, em 2017, o exame forense ocorreu dentro de 24 horas em 30\% dos casos. Foi coletado Swab para detecção de sêmen, sendo que a presença de espermatozoides ao exame microscópico foi positiva em 8 casos, todos em que o exame ocorreu dentro das primeiras 24 horas do abuso. Não foi descrito de qual região foi realizada a coleta. Desses casos, apenas 3 são de meninos, e dentre os meninos, 1 tinha hiperemia em região anal sendo que os outros dois não tinham alterações em região anogenital. No nosso trabalho, o intervalo de 24 horas decorrido entre a alegada violência e a perícia sexológica representou $23 \%$ dos casos. A coleta de esperma da região anal foi realizada em 73 casos, e da cavidade oral, em 37 casos. Em nenhum caso houve positividade para a presença de espermatozoides. Esses dados são compatíveis com estudos sobre presença de espermatozoides no exame forense, já que são raros os resultados positivos para coleta de fluidos da cavidade oral ou da região anal ${ }^{27}$. Dentre os fatores que prejudicam a coleta de material biológico, temos o tempo decorrido entre a violência alegada e a perícia médica. Em nosso estudo, apenas $23 \%$ dos casos foram periciados em até 24 horas após a ocorrência do delito alegado, o que impossibilitou a coleta de material biológico e, consequentemente, o encontro de vestígios, na grande maioria dos casos $(77 \%)$. Esse cenário reforça a necessidade de investimento em processos de assistência precoce às vítimas, aliados a processos de investigação precoce, para que o tempo entre os atos violentos e a perícia seja diminuído, de forma a ampliar a acurácia diagnóstica da perícia médico-legal.

\section{CONCLUSÃO}

Em nosso estudo, o ato libidinoso mais referido pelos meninos foi o coito anal (25\%), seguido pela manipulação do ânus da vítima (15\%). A média da idade das supostas vítimas foi 6,85 anos, enquanto a moda foi 6 anos e a mediana, 6 anos. $\mathrm{O}$ agressor mais frequentemente referido foi um conhecido, em $25 \%$ dos casos, seguido pelo pai, com $23 \%$ e colega da escola, em $9 \%$. O exame pericial foi realizado em até 24 horas após o alegado ato violento em apenas $23 \%$ dos casos. Do total de casos, $10 \%$ apresentaram lesão corporal, todos de natureza leve. Não houve casos de positividade da coleta de espermatozoides seja para a região anal seja para a cavidade oral, o que prejudica o diagnóstico médico legal da ocorrência de violência sexual. Em muitos casos de violência sexual, em especial contra crianças, os atos libidinosos praticados podem não deixar vestígios, não havendo materialidade do crime que possa ser comprovada pela prova técnica pericial, sendo necessária a avaliação conjunta com outros tipos de provas para se fazer a justiça social.

Gomes Filho CH, Miziara ID, Uzelin NCR, Gianvecchio DM. Study of 127 cases of sexual violence against vulnerable males who attended the program Bem Me Quer in 2014. Saúde, Ética \& Justiça. 2021;26(1):13-20.

\begin{abstract}
Sexual violence is any unwanted sexual act against someone's sexuality, practiced by any person regardless of their relationship with the victim and in any scenario. Literature about sexual violence against male children is scarce. The goal of this work was to describe the libidinous acts referred to vulnerable males who attended the Program Bem Me Quer, of the Department of Public Safety of the State of São Paulo, in 2014. Secondary goals included the description of the age of the alleged victims, interpersonal relationship with the alleged aggressor, the time interval between the alleged violence and the forensic examination, presence of body injuries and positive identification of sperm. A retrospective analysis of data collected from forensic examinations in 2014 was carried out. After the inclusion and exclusion criteria were applied, we studied the reports of 127 vulnerable males. The most frequently cited alleged libidinous act was anal intercourse (25\%). The average age of the alleged victims was 6,85 years. The most common alleged aggressor was a known person (25\%). In $23 \%$ of the cases, the forensic examination was carried out within 24 hours. A total of $10 \%$ of the cases had mild body injuries. There was no positive identification of sperm, which hinders the verification of sexual violence.
\end{abstract}

KEY WORDS: Child Abuse; Boys; Forensic Medicine. 


\section{REFERÊNCIAS}

1. Jewkes R, Sen P, Garcia-Moreno C. Sexual violence. In: Krug EG, Dahlberg LL, Mercy JA, Zwi AB, Lozano R, editors. World report on violence and health. Geneva: World Health Organization; 2002. p. 147-74.

2. U.S. Department of Health \& Human Services. Centers for Disease Control and Prevention. Injury Center. Preventing sexual violence [Internet]. Atlanta; 2021. [Acesso em 2021 mar. 02]. Disponível em https://www.cdc.gov/violenceprevention/ sexualviolence/fastfact.html

3. Roche AJ, Fortin G, Labbé J, Brown J, Chadwick D. The work of Ambroise Tardieu: the first definitive description of child abuse. Child Abuse Negl. 2005;29(4):325-34. DOI: https://doi. org/10.1016/j.chiabu.2004.04.007

4. Heinrich LB. Care of the female rape. Nurse Pract. 1987;12(11):9-12, 16-18, 23-7.

5. Hohendorff JV, Habigzang LF, Koller SH. Violência sexual contra meninos: dados epidemiológicos, características e consequências. Psicol USP. 2012;23(2):395-416. DOI: https:// doi.org/10.1590/S0103-65642012005000007

6. Prado SF. Dimensões da violência sexual contra meninos sob a ótica de gênero: um estudo exploratório [tese] [Internet]. Brasília: Universidade de Brasília; 2006. [Acesso em 2021 mai. 02]. Disponível em: https://repositorio.unb.br/ handle/10482/2302

7. Brasil. Presidência da República, Subchefia para Assuntos Jurídicos. Lei no ${ }^{\circ} .069$, de 13 de julho de 1990. Dispõe sobre o Estatuto da Criança e do Adolescente e dá outras providências [Internet]. Brasília, DF;1990. [Acesso em 2021 mar. 01]. Disponível em: http://www.planalto.gov.br/ccivil_03/leis/ 18069.htm

8. Brasil. Presidência da República, Subchefia para Assuntos Jurídicos. Decreto-Lei no 2.848, de 07 de dezembro de 1940. Código Penal [Internet]. Rio de Janeiro, RJ;1940. [Acesso em 2021 mar. 01]. Disponível em: http://www.planalto.gov.br/ ccivil_03/decreto-lei/del2848compilado.htm

9. Ferreira MS, Zerbini T, Cintra RB. Aspectos éticos e jurídicos da perícia médico-legal em Sexologia Forense. In: Cohen C, Oliveira RA, editores. Bioética, Direito e Medicina. $1^{\mathrm{a}}$ ed. Barueri: Manole; 2020. p.582.

10. França GV. Medicina Legal. $11^{\mathrm{a}}$ ed. Rio de Janeiro: Guanabara Koogan; 2017.

11. Brasil. Conselho Federal de Medicina. Resolução CFM n 2.217, de 27 de setembro de 2018. Aprova o Código de Ética Médica [Internet]. Brasília, DF; 2018. [Acesso em 2021 mar. 02]. Disponível em: https://www.cremers.org.br/pdf/ codigodeetica/codigo_etica.pdf

12. Giardino AP, Finkel MA. Evaluating child sexual abuse. Pediatr Ann. 2005;34(5):382-94. DOI: https://doi.org/10.3928/00904481-20050501-12

13. Magalhães T, Ribeiro CS, Jardim P, Nuno Vieira D. Procedimentos forenses no âmbito da recolha de informação, exame físico e colheita de vestígios em crianças e jovens vítimas de abuso físico e/ou sexual. Acta Medica Portuguesa. 2011;24(2):339-48.

14. Magalhães T, Dinis-Oliveira RJ, Silva B, Corte-Real F, Nuno Vieira D. Biological evidence management for DNA analysis in cases of sexual assault. Scientific World Journal. 2015;2015:365674. DOI: https://doi.org/10.1155/2015/365674

15. São Paulo. Assembleia Legislativa do Estado de São Paulo.
Decreto $^{\circ}$ 46.369, de 14 de dezembro de 2001. Dispõe sobre $\mathrm{o}$ atendimento do Programa BEM-ME QUER [Internet]. São Paulo, SP; 2001. [Acesso em 2021 abr. 29]. Disponível em: https://www.al.sp.gov.br/repositorio/legislacao/decreto/2001/ decreto-46369-14.12.2001.html\#: : :text=Constitui\%20 objeto $\% 20$ deste $\% 20$ Termo $\% 20$ de,quatorze) $\% 20$ anos $\% 20$ de $\% 20$ idade $\% 2 \mathrm{C} \% 20 \mathrm{v} \% \mathrm{C} 3 \%$ ADtimas.

16. Dicionário Priberam da Língua Portuguesa [online]. "Felação". [Acesso em 2021 mai. 02]. Disponível em: https://dicionario. priberam.org/fela\%C3\%A $7 \% \mathrm{C} 3 \% \mathrm{~A} 30$

17. Hobbs CJ, Osman J. Genital injuries in boys and abuse. Arch Dis Child. 2007;92(4):328-31. DOI: https://doi.org/10.1136/ adc.2006.111195

18. Martins CBG, Jorge MHPM. Abuso sexual na infância e adolescência: perfil das vítimas e agressores em município do sul do Brasil. Texto contexto - enferm. [Internet]. 2010 [Acesso em 2021 mar. 02];19(2):246-55. Disponível em: http:// www.scielo.br/scielo.php?script=sci arttext\&pid=S0104-

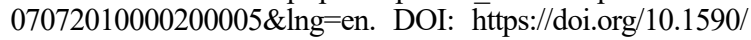
S0104-07072010000200005

19. Guimarães JATL, Villela WV. Características da violência física e sexual contra crianças e adolescentes atendidos no IML de Maceió, Alagoas, Brasil. Cad Saúde Pública [Internet]. 2011 [Acesso em 2021 mar. 02];27(8):1647-53. Disponível em: http:// www.scielo.br/scielo.php?script=sci_arttext\&pid=S0102-

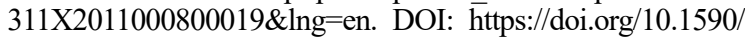
S0102-311X2011000800019

20. Modelli MES, Galvão MF, Pratesi R. Child sexual abuse. Forensic Sci Int. 2012;217(1-3):1-4. DOI: https://doi. org/10.1016/j.forsciint.2011.08.006

21. Silva WS, Barroso-Junior UO. Child sexual abuse confirmed by forensic examination in Salvador, Bahia, Brazil. Am J Forensic Med Pathol. 2017;38(1):54-8. DOI: https://doi.org/10.1097/ PAF.0000000000000283

22. Elgendy IS, Hassan NA. Medicolegal study of child sexual abuse in Greater Cairo, Egypt, during a 7-year period: 20052011. Am J Forensic Med Pathol. 2013;34(4):335-41. DOI: https://doi.org/10.1097/PAF.0000000000000043

23. Hohendorff JV, Costa LS, Habigzang LF, Koller SH. Documentary analysis of cases of sexual violence against boys reported in Porto Alegre. Paidéia (Ribeirão Preto). 2014;24(58):187-96. DOI: https://doi.org/10.1590/198243272458201406

24. Bruni M. Anal findings in sexual abuse of children (a descriptive study). J Forensic Sci. 2003;48(6):1343-6.

25. Salter M. Child sexual abuse. In: Dekeseredy WS, Dragiewicz M, editors. Routledge Handbook of Critical Criminology. $2^{\text {nd }}$ ed. New York: Routledge; 2018.

26. Aded NLO, Dalcin BLGS, Cavalcanti MT. Estudo da incidência de abuso sexual contra crianças no Rio de Janeiro, Brasil: an incidence study. Cad Saúde Pública [Internet]. 2007 [Acesso em 2021 mar. 02];23(8):1971-5. Disponível em: http:// www.scielo.br/scielo.php?script=sci_arttext\&pid=S0102311X2007000800024\&lng=en. DOI: $\bar{h}$ ttps://doi.org/10.1590/ S0102-311X2007000800024

27. Lavelle J. Forensic evidence collection. In: Giardino AP, Alexander R, editors. Child maltreatment: a clinical guide and reference. $3^{\text {rd }}$ ed. Canada: G.W. Medical Publishing, Inc.; 2005. p.856-60. 